\title{
Three Near-Death Experiences with Premonitions of What Could Have Been
}

\author{
Barbara A. Walker, Ph.D. \\ Eastern Illinois University \\ William J. Serdahely, Ph.D. \\ Montana State University \\ Lori J. Bechtel, Ph.D. \\ Pennsylvania State University, Altoona Campus
}

\begin{abstract}
We analyze three near-death experiences involving a unique type of prophetic vision that has not previously been reported in the literature. These visions involve a brief glimpse of what circumstances would have been like for the near-death experiencers' family in the aftermath of the experiencers' deaths, had they actually died.
\end{abstract}

Prophecy has long been a popular theme related to death and dying. During the past decade Kenneth Ring and others have reported on a small number of anecdotal cases dealing with two relatively uncommon aspects of the near-death experience: the personal flashforward and the prophetic vision (Audette, 1981; Ring, 1982, 1984, 1988; Grey, 1985).

Dr. Walker is with the Department of Health Studies, Eastern Illinois University; Dr. Serdahely is Professor of Health Science, Montana State University; and Dr. Bechtel is Assistant Professor of Health Education at the Pennsylvania State University Altoona Campus. Requests for reprints should be addressed to Dr. Walker at the Department of Health Studies, Eastern Illinois University, Charleston, IL 61920. 
In reports of the personal flashforward, experiencers typically describe an image or vision of their lives in their near future. Memory of the personal flashforward is generally recalled in the form of déjà $v u$ at the time the event actually occurs. In reports of the prophetic vision, experiencers claim to be given a glimpse of future global events, such as major earthquakes, nuclear explosions, and famine, rather than personal events. These global prophetic visions are often revealed through an association with a spiritual guide or a being of light (Ring, 1984).

During the past year, three near-death experiences (NDEs) have come to our attention that include an additional type of prophecy not reported in the literature to date. This type of prophecy involves being given a brief glimpse of what it would have been like for the experiencers' family, had the experiencers actually died. One of us (B.A.W.) received the first of these cases by written correspondence, and the second through a telephone interview; another of us (W.J.S.) collected the third case through written correspondence. We present below a brief description of each account, using pseudonyms for the experiencers to facilitate discussion of each case.

\section{Case 1: Lisa}

At the present time Lisa is 35 years old, and at the time of her written correspondence she was 34 . Lisa reported having undergone at the age of 4 a near-death experience that reached Ring's stage 2 (Ring, 1980). At that time Lisa had been extremely ill with influenza and bronchitis.

On the day of the near-death event, Lisa's mother was very busy trying to fulfill needed household chores while simultaneously quite concerned about her daughter's welfare. In order to keep a closer eye on Lisa while attending to her housework, her mother asked Lisa to lie down on a mattress she had placed on the kitchen floor. Shortly thereafter Lisa's condition worsened and her near-death experience ensued:

I remember lying on my stomach and feeling sick and weak. At one point I felt like I would either vomit or pass out. I took a deep breaththe next thing I knew I was floating up (backward) away from my physical body-right up to the ceiling. The very first thought I had was, "What am I doing up here if I'm down there?" Then it dawned on me. "This must be my soul, and I must be dead." 
At this point in her NDE, Lisa began to reflect upon the implications her imminent death might have upon her parents. She suddenly recalled that her parents had already experienced the loss of their first child, and Lisa was concerned about how her death as well might affect them. Immediately after this thought a revealing premonition was disclosed to her:

I asked myself, "What would happen to my parents if I left them?" No sooner had I finished the thought than the answer was shown to me. I suddenly saw the images of my parents and grandparents right before me-about five feet away-on what resembled a wide projector screen-only this was in 3-dimensional color! They were grieving badly, and they looked absolutely drained. It was an extremely sad moving picture. I decided I couldn't let them go through that. Even with all my concerns I had to admit that I felt great! I had no pain and no fear. I felt peaceful and perfect!

While in this near-death state, Lisa was acutely aware of her own "soul body." She made an effort to look down and around to see what this body looked like, but all she could see was a grayish mist. Lisa then made an unsuccessful attempt to reunite her soul body with her physical, earthly body that lay lifeless below her. Frustrated by this initial effort, she focused her attention on trying to figure out how to move from one place to another in this new state of existence. The answer came to her immediately. She realized that all she needed to do was to let her mind tell her soul body where to move, and in so doing her soul would travel to that destination. Lisa also had little doubt that she could move right through the wall and journey outside the house if she so desired. She described the sensations she experienced while undertaking such an attempt as follows:

As I was passing right through the wall I could feel everything inside of it - the wood, the wiring, the nails-but it didn't hurt. In fact, it felt great - as if everything was alive, and I could feel all the atoms and molecules.

Once outside the house, Lisa again focused her attention on her family. Her last thought before reuniting with her physical body was: "Oh, oh. What if I can't get back?" She doesn't remember anything about the actual reentry process.

When Lisa regained consciousness and opened her eyes she saw her mother kneeling over her, crying. Her mother responded by saying, "Oh, thank God," and then went on to tell Lisa that she had been 
trying to awaken her for about five minutes. When Lisa tried to tell her mother about what she had just experienced, her mother told her that she had only been dreaming. When Lisa insisted that the events she had undergone were very real and that she wanted to tell everybody what had happened, her mother asked her not to tell people, as they might think that she was crazy.

\section{Case 2: Paula}

Paula is currently 30 years old, and at the time of her telephone interview was 29 . She stated that she was 8 or 9 years old when she had her near-death experience, which reached Ring's stage 5.

Paula had been living in the New York metropolitan area when a childhood friend invited her to accompany her on a family visit to rural New York. During the course of their visit, Paula and her friend decided to go swimming in a nearby pond. At some point during this swim, Paula found herself uncomfortably far from shore and struggling to get back. When she had nearly made it to the banks of the pond, she felt herself drowning. At that moment she was suddenly aware of an incredibly bright light to her left, which she knew to be God because of the enormous love she felt from it. To her right she saw pastel-colored spiritual entities that she identified as seven angels.

She then found herself traveling swiftly down a road, stopping at a house. Paula could see her parents standing in the window reading the newspaper and crying. Upon closer examination, Paula realized the reason for her parents' grief: they were reading her obituary! At that moment, Paula was revived from her near-drowning and instantaneously returned to her physical body.

\section{Case 3: Natalie}

Natalie was $17^{1 / 2}$ years old at the time of her interview and 15 years old at the time of her NDE, which reached Ring's stage 4. Natalie had experienced some respiratory distress and was driven to her pediatrician's clinic. While at the clinic, she experienced a severe asthmatic attack, lost consciousness, and had a seizure.

Natalie suddenly found herself in a tunnel, at the end of which she could see a brilliant light. While in this tunnel, two "light figures" came to her. Natalie felt that these beings were a part of the same 
brilliant light she could see at the end of the tunnel, and described them as friendly. With one on each side of her, the light figures took hold of her hands and together they slowly floated towards the light at the end of the tunnel. Natalie was exuberant and anxious, as she wanted to reach the brilliant light as soon as possible. She could also see other light figures, none of whom were recognizable, waiting to greet her at the tunnel's end.

While traveling down the tunnel with these light figures, images from her past began to float over her head. Suddenly Natalie saw an image of her mother, father, sister, and niece, all looking extremely sad. Natalie knew what she was seeing was a premonition of what her relatives would look and feel like if she were to die at that time.

Although Natalie personally felt elated about her out-of-body condition, she worried about the consequences her death would have on her family. Upon seeing the image of her family and feeling her concern for them, the light figures set her down. She then walked back through the tunnel and returned to her physical body.

\section{Discussion}

The common factor that sets these three cases apart from those found in the current near-death literature is the type of prophetic vision experienced by all three. Prophetic visions are hardly a new phenomenon; however, we know of no previous accounts in the literature of a near-death prophetic case in which the experiencer was able to view the possible emotional aftereffects of his or her death on parents and loved ones.

Although the subjects in these cases experienced a similar type of near-death premonition, the contents of their NDEs are quite different. A comparative analysis of these three cases follows. Because the written correspondence with Lisa and Natalie were more comprehensive than the telephone interview with Paula, commentary concerning Lisa and Natalie are more elaborate.

One of the most impressive aspects of these three cases is the acute insightfulness with which each premonition was recalled from childhood. Though described in the context of an adult intellect, as recalled the perceptions of each situation transcended the normal analytical reasoning of a young child. This is particularly evident in the advanced cognitive reasoning expressed by Lisa at the age of 4 . This type of precocious cognitive development revealed in NDEs during childhood 
or even at birth has been noted in previous reports (Morse, 1983; Morse, Castillo, Venecia, Milstein, and Tyler, 1986; Serdahely, 1989-90; Serdahely and Walker, 1990).

One of us (B.A.W.) interviewed a 26-year-old man who had experienced an NDE during his early childhood. He could not recall his specific age, but he estimated that he was between 1 and 2 years old. The young man noted that this near-death occurrence was, in fact, his first conscious memory. While sitting in a playpen, he swallowed a marble that lodged in his throat, blocking his air supply. The infant then left his body and traveled towards a brilliant white light that communicated with him. He explained that although he did not have a command of the English language at that time, the light told him that he had things yet to do and that he would have to return. Communication was instantaneous and comprehensive, despite the apparent barriers of age, developmental reasoning, and lack of formal language skills.

Is a young child capable of obtaining the ability to process information and possess knowledge beyond normal, earthly developmental parameters while in an out-of-body near-death state? While this concept is intriguing, it is open to skepticism. An alternative hypothesis is that the detail with which these childhood NDEs are described might be attributed to retrospective adult interpretation.

Mode of death does not appear to be a significant factor in producing this type of prophetic vision, as Lisa's NDE evolved from an illness, Paula's resulted from a near-drowning, and Natalie's resulted from an acute asthma attack. This is consistent with prior reports that mode of death does not influence type of experience (Ring, 1980; Ring and Franklin, 1981-82; Sabom, 1982; Twemlow, Gabbard, and Coyne, 1983; Green and Friedman, 1983; Sullivan, 1984).

Although each of these three subjects experienced a similar premonition of what could have been in the event of death, there are numerous differences in the circumstances surrounding these visions.Lisa consciously asked the question, "What would happen to my parents if I left them?", and upon asking this question she was immediately shown the answer on a three-dimensional screen. In contrast, Paula's premonition occurred spontaneously, without any forethought. Furthermore, Paula's spiritual body traveled down a road and personally viewed the events to take place, rather than viewing them on a screen. Natalie's vision also occurred spontaneously; in her case, however, she viewed her premonition in the context of a life review while traveling down the tunnel towards the being of light. 
Lisa's return to her body also parallels a number of core NDEs in which experiencers, though peaceful and euphoric in their out-of-body states, choose to return to an earthly existence out of concern for loved ones left behind (Ring, 1984). After viewing the extreme sadness to be experienced by her parents and grandparents, Lisa chose not to put them through such a horrific ordeal but to return. Similarly, although Natalie felt jubilant about her near-death condition, her concern for her family seemed to prompt the light figures to let her go, allowing her to return to her body. A conscious decision to return to earthly existence was not evident in Paula's NDE.

Another major difference among these cases is the presence of spiritual entities. Natalie was immediately greeted by two friendly light figures who guided her down a tunnel towards a brilliant light, and could also see similar light figures at the end of the tunnel. Paula encountered seven pastel-colored beings she identified as angels, and like Natalie was aware of an incredibly bright light that she knew to be God. Lisa's NDE did not involve any interaction with supernatural beings, but she did interact with a sense of life energy in the atoms and molecules within seemingly inanimate earthly objects.

As with Ring's analysis of the more common prophetic visions, one can reach a variety of conclusions regarding these two cases. A psychiatric interpretation might assume that these individuals were troubled and that their visions evolved as a result of their psychopathology. A prophetic interpretation might suggest that these visions were conditional circumstances, in that they represented situations that could not occur unless certain life changes were made. Finally, an alternate futures interpretation would suggest that they were visions of an alternate universe that exists concurrently with our own; that is, the outcome seen in a prophetic vision may actually take place, but in another parallel world (Ring, 1984, 1988).

Although we obviously cannot draw global implications about such prophecy from three retrospective cases, the content of these examples is nevertheless worthy of consideration. Perhaps other near-death experiencers have experienced similar prophetic visions but are reluctant to discuss them. Lisa was warned as a child not to discuss her near-death event and as a result remained quiet about the incident for nearly thirty years.

In the 1946 Frank Capra movie "It's a Wonderful Life," George Bailey was blessed with a vision of what life would have been like for those he knew and loved, had he never been born. Although the cases cited here do not reflect this exact scenario, the individuals seemed to draw 
parallel lessons. The moral of that film was that we all do matter, that we all do touch one another's lives in significant ways even when we may not be consciously aware of it.

The prophetic visions described here seem to have served a similar purpose in reminding the experiencers that we do indeed impact upon others more than we realize. These three prophetic visions may have been the impetus to will the spirit to return to bodily life to save loved ones the pain of grief. As is the case with all NDEs, though the reported cases are unique to each individual, they strike universal themes. Though it would be premature to speculate on specific causes or functions on the basis of only three cases, we believe that the reporting of additional near-death experiences with premonitions of what could have been will enable specific inferences to be drawn.

\section{References}

Audette, J. (1981). Visions of Knowledge in NDEs. Vital Signs, 1(4), 5-6.

Green, J.T., and Friedman, P. (1983). Near-death experiences in a southern California population. Anabiosis: The Journal of Near-Death Studies, 3, 77-95.

Grey, M. (1985). Return from death. London, England: Arkana.

Morse, M.L. (1983). A near-death experience in a 7-year-old child. American Journal of Diseases of Children, 137, 959-961.

Morse, M.L., Castillo, P., Venecia, D., Milstein, J., and Tyler, D. (1986). Childhood neardeath experiences. American Journal of Diseases of Children, 139, 595-600.

Ring, K. (1980). Life at death: A scientific investigation of the near-death experience. New York, NY: Coward, McCann and Geoghegan.

Ring, J. (1982). Precognitive and prophetic visions in near-death experiences. Anabiosis: The Journal of Near-Death Studies, 2, 47-74.

Ring, K. (1984). Heading toward omega: In search of the meaning of the near-death experience. New York, NY: Morrow.

Ring, K. (1988). Prophetic visions in 1988: A critical reappraisal. Journal of Near-Death Studies, 7, 4-18.

Ring, K., and Franklin, S. (1981-82). Do suicide survivors report near-death experiences? Omega, 12, 191-208.

Sabom, M.B. (1982). Recollections of death: A medical investigation. New York, NY: Harper and Row.

Serdahely, W.J. (1989-90). A pediatric near-death experience: Tunnel variants. Omega, $20,55-62$.

Serdahely, W.J., and Walker, B.A. (1990). A near-death experience at birth. Death Studies, 14, 177-183.

Sullivan, R.M. (1984). Combat-related near-death experiences: A preliminary irvestigation. Anabiosis: The Journal of Near-Death Studies, 4, 143-152.

Twemlow, S.W., Gabbard, G.O., and Coyne, L. (1982). A multivariate method for the classification of pre-existing near-death conditions. Anabiosis: The Journal of NearDeath Studies, 2, 132-139. 